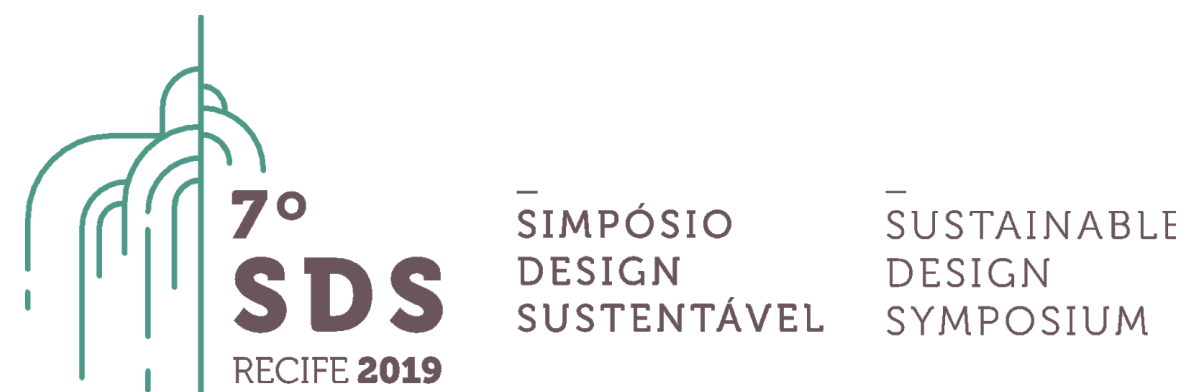

\title{
REAPROVEITAMENTO DOS RESÍDUOS DO JUPATI (RAPHIA TAEDIGERA) E SUA APLICABILIDADE NA PRODUÇÃO DE MOBILIÁRIO
}

\author{
Amanda Paloma Bahia dos Santos (bacharel) ${ }^{1}$, Elisa Batista Conrado Martins (bacharel) ${ }^{2}$, Yasmim Mariana Baia Silva \\ (bacharel) ${ }^{3}$, Ninon Rose Tavares Jardim (mestre) ${ }^{4}$ \\ ${ }^{1}$ Universidade do Estado do Pará,Design,amanda.pba.santos@gmail.com \\ ${ }^{2}$ Universidade do Estado do Pará, Design, elisabatistacm@gmail.com \\ 3 Universidade do Estado do Pará, Design,yasmimbsilva.11@gmail.com \\ ${ }^{4}$ Universidade do Estado do Pará, Design,ninonjardim@gmail.com
}

Resumo. O presente artigo tem como objeto de estudo o resíduo proveniente da produção artesanal dos produtos de Jupati (Raphia Taedigera), bem como sua aplicabilidade na produção de mobiliário e artigos de decoração. Matéria-prima que é descartada após a retirada da "tala" que é comumente usada na confecção do matapi, armadilha artesanal de pesca do camarão, e de cestos em diversos tamanhos, por artesãos do município de São Sebastião da Boa Vista, no Marajó-PA. A pesquisa se inicia com o estudo da matéria-prima $e$ experimentações através de análises de estratégias para aproveitar suas características físicas, de resistência e textura. Por fim, foram aplicadas metodologias de projeto de Design e técnicas de criatividade para a construção dos produtos, bem como seus conceitos. Ao final da pesquisa foram criadas duas peças, com bons resultados da aplicabilidade do material na confecção dos produtos.

Palavras-chave. Resíduos; Jupati; Mobiliário.

\section{Introdução}

A Amazônia Marajoara é muito rica no que se refere a aspectos culturais e sustentáveis. Há muito a se explorar e repensar na produção moveleira da região, seja no emprego de novos materiais, seja na busca de uma identidade local. O foco da produção moveleira e sua identidade estava centrado na matéria-prima, na madeira. Com a exploração indiscriminada dessa matéria-prima e sua escassez no mercado local, esse setor perdeu bastante o seu potencial, muitos moveleiros partiram para a utilização do MDF para se manter no mercado. Utilizar fontes sustentáveis, evitando desperdícios e exploração indevida, significa reinventar essa área de forma consciente, possibilitando a aplicação de valores acerca da sustentabilidade que são trabalhados na área de design. 
Nesse sentido, a partir de pesquisas anteriores ${ }^{1}$, identificou-se que o Jupati (Raphia Taedigera), matéria-prima utilizada na produção artesanal de acessórios de moda, peças decorativas, cestarias e matapis (armadilha artesanal de pesca de camarão), no município de São Sebastião da Boa Vista - Marajó/PA, poderia ser um potencial material para o produção moveleira do estado, pois seu pecíolo (parte de onde é extraída a matéria-prima do artesanato) é descartado durante o processo. Esse fato chamou a atenção das pesquisadoras, e como o papel do design é buscar soluções para problemáticas apresentadas, o reaproveitamento do resíduo do Jupati poderá contribuir para um ciclo mais sustentável da produção moveleira local.

Para tanto, foi necessário (a) estudar as características do Jupati; (b) identificar pesquisas já realizadas acerca da matéria-prima; (c) experimentar o material na aplicação em protótipos; (d) desenvolver projeto de design de produtos e mobiliário utilizando a matéria-prima; e (e) analisar o resultado final indicando melhorias e aplicabilidade para o mobiliário.

É importante salientar que a atividade de projetação dos produtos para a presente pesquisa se ateve ao processo de experimentar as possibilidades de melhor aproveitamento do material, no que se refere aos seus aspectos sensoriais. As características voltadas a resistência mecânica tiveram como base pesquisas na literatura para avaliação de alternativas de estruturações que proporcionassem maior segurança no momento do uso, não sendo realizado nesta pesquisa ensaios mecânicos.

O resíduo na produção moveleira, além de proporcionar um destino novo para um material que seria descartado, dará ao próprio jupati um novo ciclo de vida, aumentando seu tempo útil, aliando a sustentabilidade com a geração de produtos, usando o Design como estratégia de produção e valorização de um bem rico e que se mostra detentor de grande potencial.

\section{Materiais e métodos}

A definição do material estudado partiu-se do conhecimento do processo produtivo artesanal dos produtos de Jupati. Hoje, da matéria-prima (figura 1 e 2) é utilizada a fibra (parte interna) e a tala (parte externa) na produção e o restante do pecíolo é descartado gerando resíduos do material, como mostra os apontamentos de Jardim (2013):

Jupati (Raphia Taedigera) que é a matéria prima utilizada pelos artesãos do município de São Sebastião da Boa Vista, palmeira nativa da flora amazônica em aspecto de touceira com aproximadamente 2 a $3 \mathrm{~m}$ de altura, mas com folhas compridas que podem atingir até 15 metros (JARDIM, 2007, p.2 apud JARDIM, 2013, p.18).

Figura 1 - Estruturas das folhas pinadas e palmadas sendo o jupati palmeira de folhas pinadas

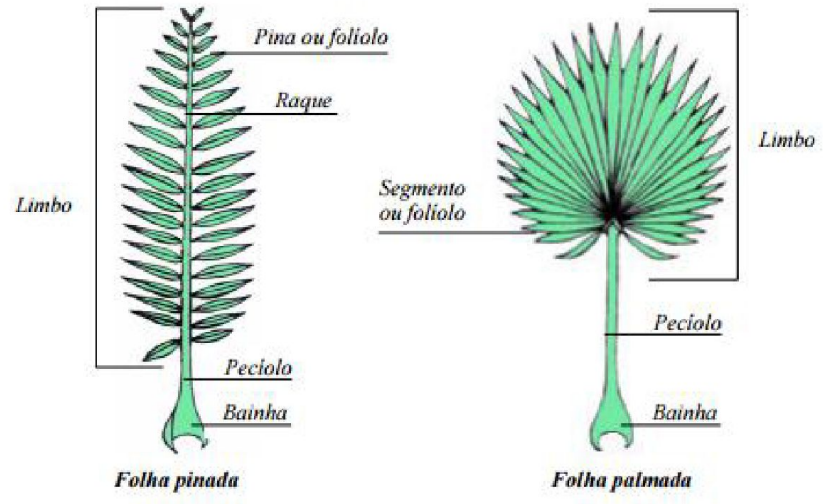

Fonte: SODRÉ, 2005, p. 14

\footnotetext{
${ }^{1}$ Mais detalhes sobre a matéria-prima, o processo produtivo e seus saberes e fazeres ver Jardim (2013; 2007) e Costa e Simões (2011)
} 
Figura 2 - Extração e limpeza da vara do jupati

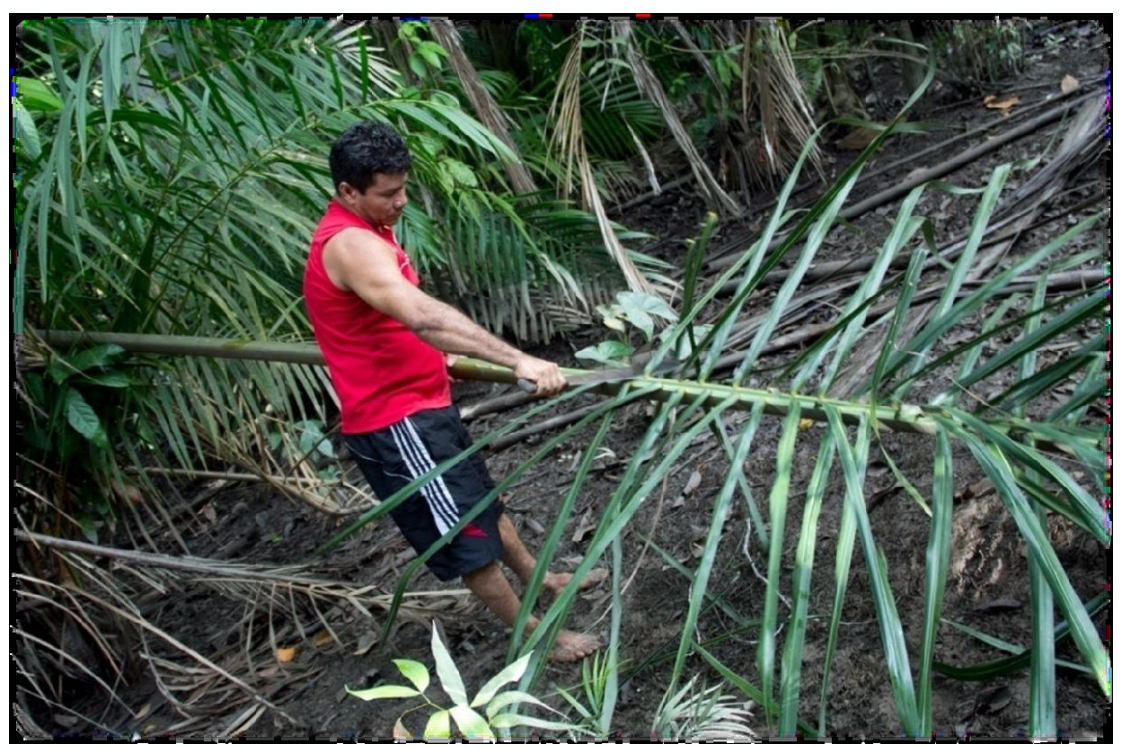

Fonte: JARDIM, 2013, p. 132

O Jupati (Raphia Taedigera) é uma palmeira amazônica que cresce em áreas de várzea e que é bastante utilizada no artesanato, sendo São Sebastião da Boa Vista a cidade que se destaca nesse saber fazer.

[...] O município de São Sebastião da Boa Vista, inserido na microrregião dos furos de Breves, pertencente à mesorregião do Marajó se destaca na confecção de diversos objetos artesanais. $O$ pecíolo é região da planta de onde provém a tala e as fibrilas, matéria prima utilizada no artesanato. A tala é o revestimento externo do pecíolo, constituída por fibras duras, utilizada na fabricação do matapi, pari, cestas, balaios, paneiros, armações de pipas e gaiolas para passarinhos, enquanto as fibrilas são originadas da medula, que é a parte interna do pecíolo, constituída por um tecido parenquimático que envolve as fibrilas. Essas se apresentam compridas, cilíndricas, macias, amarelo-brilhantes e são usadas na confecção de chapéus, bolsas e revestimento de garrafas (JARDIM 2013, p. 18).

A aplicabilidade dessa matéria-prima no processo de design partiu de pesquisa de campo vivenciada em pesquisas anteriores, onde se observou a forte relação dos artesãos com a natureza e como esta influencia na produção de seus artefatos, seja na extração da matéria-prima, seja no processo produtivo. Nesse sentido, a biomimética surgiu como possibilidade temática para o desenvolvimento dos protótipos da referida pesquisa. Muito pode ser aproveitado das interações e características da natureza; suas formas, funções e estruturas possibilitam diversas analogias para a concepção de produtos. Diante disso, aplicou-se o brainstorming como ferramenta de geração de conceito, que culminou com a expressão "Da floresta para o ambiente" e de sua relação entre rural e urbano que guia, de forma mais ampla, o processo criativo e a definição dos elementos essenciais para os protótipos.

O que dita os modos de ser e viver nesses cenários? Niemeyer (2003) corroborou para a construção da "voz visual do produto", essa metodologia trouxe a tona o "tempo", como um entre lugar nessa relação. O tempo dita os acontecimentos dentro da "floresta" e nas "cidades", movimentando as tomadas de decisões, as relações, as mudanças e os saberes e fazeres. Assim, as características da coleção de mobiliário pensada para esta pesquisa foi definida em três palavras-chaves advindas do tempo como transformação: sobrevivência, metamorfose e caos. 
Figura 3 - Geração dos conceitos da coleção e de suas três linhas de produtos

\begin{tabular}{ccc}
\cline { 2 - 3 } & $\begin{array}{c}\text { CRONOLOGIA } \\
\text { (OTEMPO COMOTRANSFORMAÇÃO) }\end{array}$ & \\
\hline linha 01 & linha 02 & linha 03 \\
\hline SOBREVIVENCIA & METAMORFOSE \\
\hline FOCO & $\mid$ & $\mid$ \\
NA NATUREZA & FOCO & FOCO \\
\hline
\end{tabular}

Fonte: Autoras, 2017

Depois de considerados os conceitos propostos e análise das possibilidades do uso do material na produção de mobiliário e produtos, foram desenvolvidos croquis e feita a seleção destes, levando em conta as limitações do material no que concerne nos seus aspectos estéticos-produtivos, de modo a não comprometer a sua funcionalidade. O uso, portando, será voltado para ambientes internos devido à resistência do material e absorção da umidade.

Após o levantamento bibliográfico, a formação dos conceitos e verificação dos melhores croquis passíveis a produção, partiu-se para a elaboração das peças. No início das experimentações foram adquiridos 24 pecíolos, que foram cortados longitudinalmente no sentido das fibras, ficando no tamanho de $1,40 \mathrm{~m}$ por pecíolo. Sua espessura ficou de $3,5 \times 3,5 \mathrm{~cm}$. Os processos utilizados para a confecção foram: corte, lixamento, selagem (para redução da porosidade), verniz (isolamento do material), além das opções de encaixe através do uso de cola e parafusos.

Figura 4 - Separação da tala do pecíolo

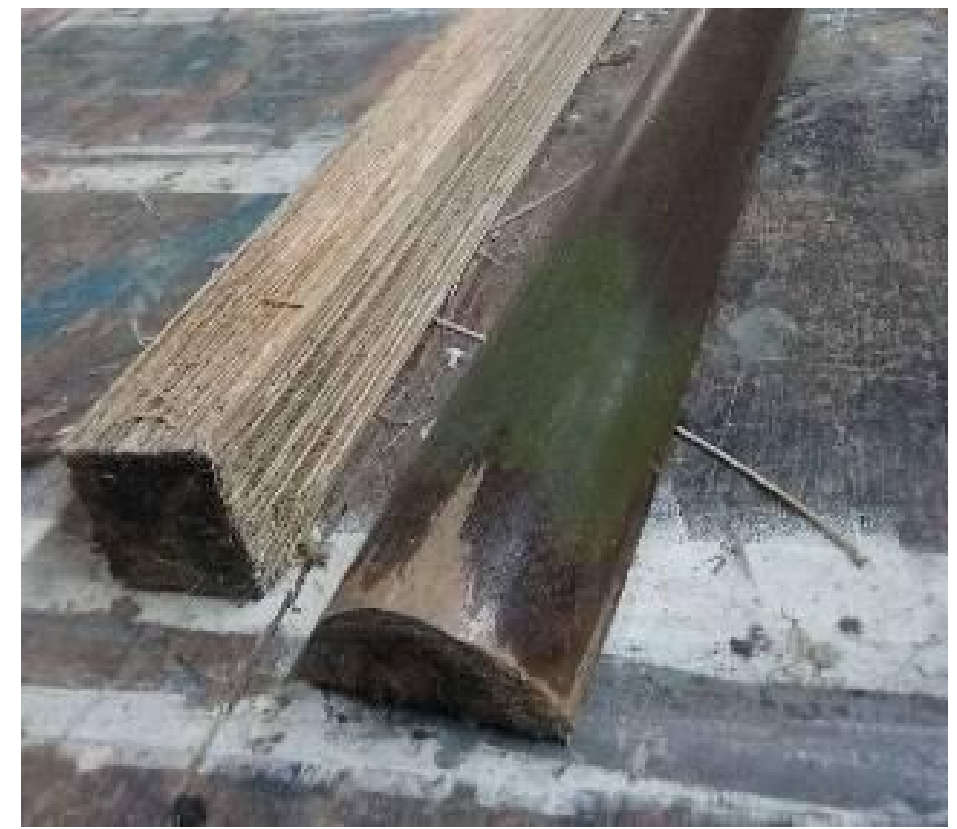

Fonte: Autoras, 2017 
Segundo Oliveira (2018) a capacidade de elasticidade do pecíolo do Jupati para compressão paralela (149 ( \pm 2$)$ Mpa) é maior do que para compressão transversal (8 $( \pm 2)$ Mpa). Outro fator que é comparado pela autora se refere a seção circular da superfície fina das células empacotadas, apresentando um comportamento similar ao de espumas flexíveis no que concerne a ação de deformação no sentido transversal às fibras. Quando se trata do sentido longitudinal, as fibras apresentam melhor desempenho mecânico pois as micro-fibrilas comportam-se como pilares atuando com sinergia apresentando maior capacidade de suportar maiores tensões aplicadas sobre elas (OLIVEIRA, 2018).

Com base nas informações colhidas na literatura no que engloba seus aspectos de desempenho mecânico, foi analisada a possibilidade de trabalhar o material de forma a dar aos produtos curvas, visto que o material tem menor resistência à tração e maior à compressão no sentido longitudinal, dessa forma, buscou-se aproveitar a compressão de forma a proporcionar maior segurança.

Figura 5 - Cortes na parte inferior do pedaço do pecíolo para aproveitamento da resistência à compressão
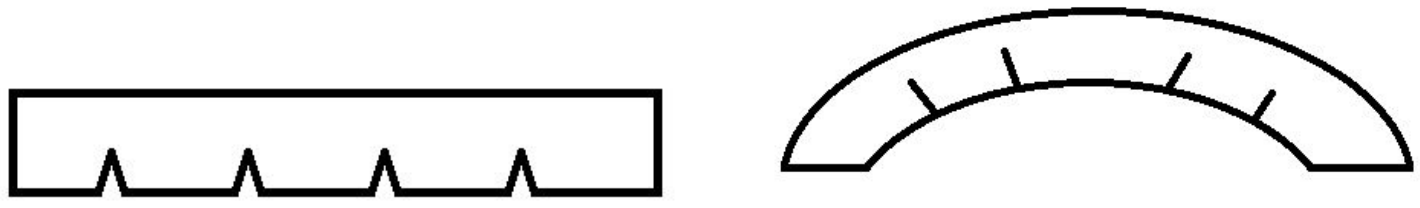

Fonte: Autoras, 2017.

No momento da aplicação da técnica, usaram-se as partes separadas e o corte foi longitudinal de forma a dar o espaçamento necessário para fazer as curvas no protótipo.

Figura 6 - Corte longitudinal no pecíolo

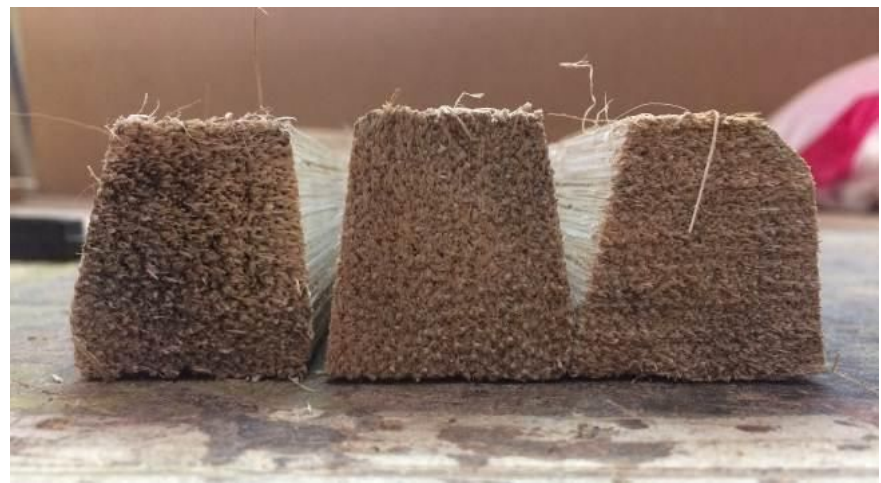

Fonte: Autoras, 2017.

O primeiro teste foi realizado no protótipo de uma luminária, da linha sobrevivência, cujo conceito pedia formas orgânicas. A princípio foi realizado o corte das peças no tamanho ideal para uma luminária de mesa, em seguida estas foram coladas e estruturadas com um vergalhão, inserido por dentro do pecíolo, que facilitou a definição da forma e na segurança no momento da fixação. Sua base também foi agrupada, colada e cortada no formato circular. Os espaçamentos provenientes dos cortes feitos anteriormente possibilitaram a resistência à compressão necessária ao objetivo do protótipo. As duas partes (corpo e base) foram unidas tornando o material único. 
Figura 7 - Confecção da luminária casulo com formas orgânicas

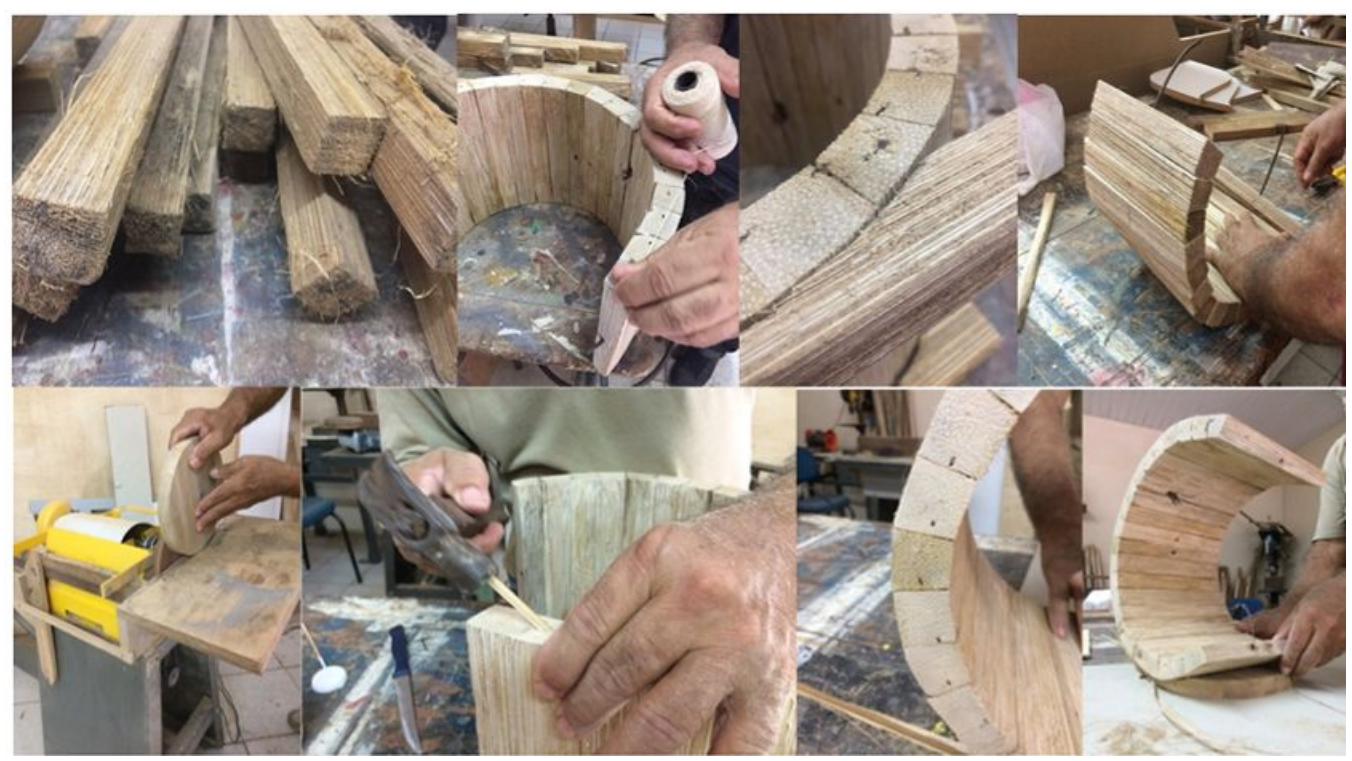

Fonte: Autoras, 2017

Outro teste realizado foi no desenvolvimento do protótipo de um banco, linha metamorfose. Utilizou-se o pecíolo cortado em forma de trapézio para melhor encaixe das peças, fixadas com cola e uma espécie de prego feito com a parte externa do próprio material popularmente conhecida como tala. O banco tem a forma de espiral sendo que a altura dos pecíolos é reduzida à medida que os raios das circunferências diminuem, proporcionando economia de material sem comprometer a estrutura e funcionalidade do protótipo.

Figura 8 - Processo de confecção do banco Áurea
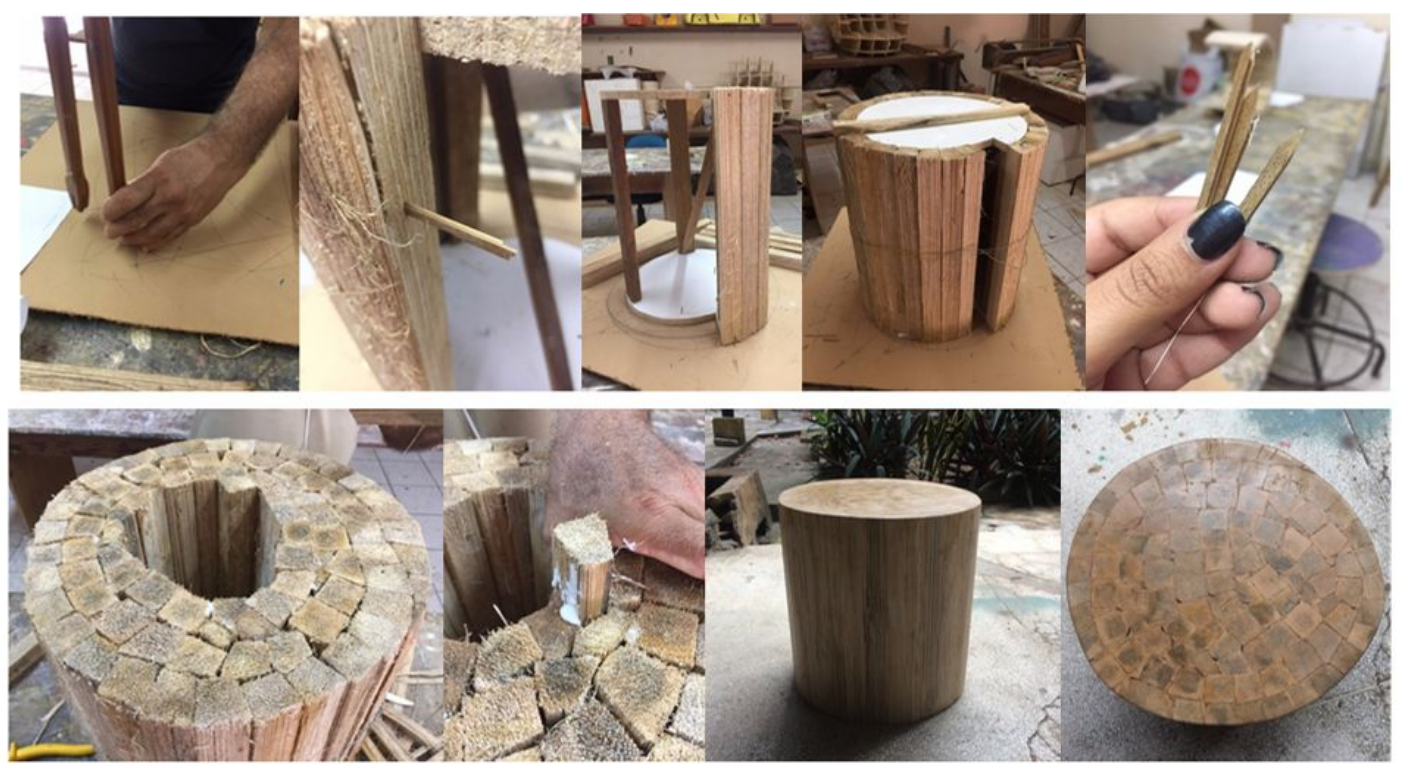

Fonte: Autoras, 2017

Ambos os protótipos foram lixados e selados para reduzir a porosidade do material e garantir maior vida útil. 


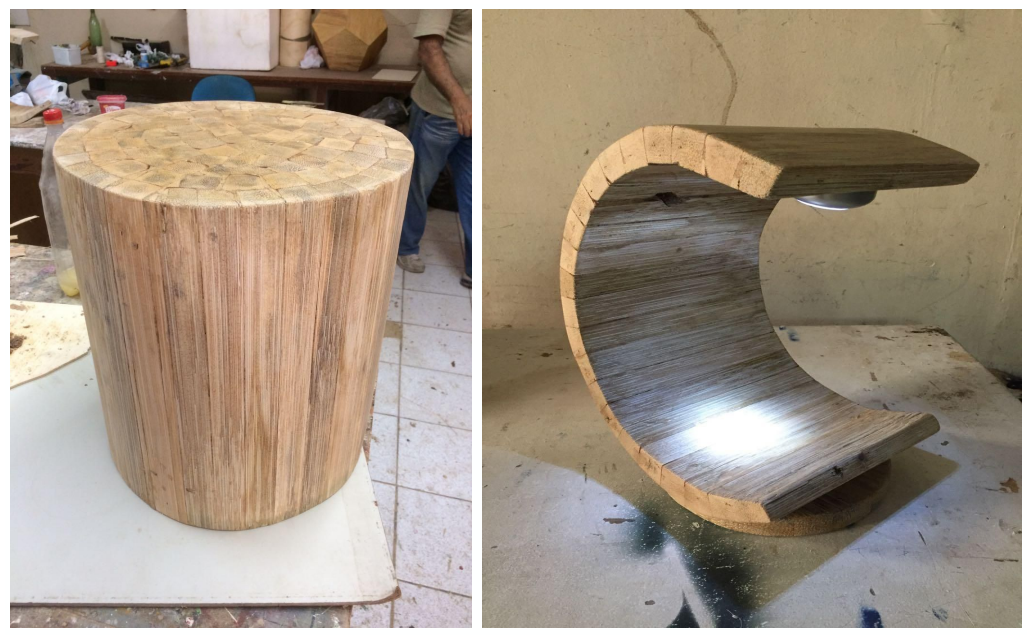

Fonte: Autoras, 2017

\section{Análise e discussão dos resultados}

A pesquisa acerca do Jupati mostrou que esta matéria prima possui aspectos similares ao miriti ${ }^{2}$ quanto ao peso leve da parte interna e relativamente leve da parte externa; textura, lisa externamente e rugosa e esponjosa internamente; cor da parte interna branco-amarelado; resistência à compressão e à tração; e diferenciando-se apenas no brilho das fibras onde o jupati apresenta brilho natural acentuado e o miriti não.

Tais aspectos foram importantes no momento de construção dos produtos de forma que suas características naturais fossem aproveitadas no projeto conceitual das peças. O material de fato se mostrou com grande potencialidade, por apresentar leveza e resistência necessária a execução de seus atributos funcionais, bem como na agregação de valor estético, por tratar-se de um material natural com cor e textura que estão sendo aproveitadas em projeto de mobiliário. No que se refere a função simbólica, a reutilização do pecíolo liga-se diretamente ao aspecto sustentável do reaproveitamento, potencializando o uso da matéria-prima e prolongando seu ciclo de vida.

\section{Conclusões}

A pesquisa trouxe uma nova perspectiva ao setor moveleiro inserindo materiais alternativos na produção visando a sustentabilidade. Atrelado a isso a definição de uma temática e conceito para elaboração dos produtos tornou o resultado do projeto mais significativo e simbólico.

O material se apresentou satisfatório na função pretendida e constatou-se que o jupati, ao contrário do que se pensava no início da pesquisa, apresenta diversas possibilidades de formas e encaixes, dando maior liberdade de criação explorando sua leveza e sua resistência, tanto à tração quanto à compressão.

Outro fator importante foi a utilização dos conhecimentos acerca de geometria para elaboração dos móveis o que proporcionou às autoras compreender na prática como a

\footnotetext{
${ }^{2}$ Miriti ou buriti, da espécie Mauritia flexuosa, é uma palmeira abundante na região amazônica e bastante utilizada por comunidades ribeirinhas, na alimentação e produção de artesanato popular. As fibras são extraídas da porção central do pecíolo esponjosa cuja a parte externa é revestida por uma superfície mais resistente (Santos, 2010).
} 
transdisciplinaridade aplicada aos projetos de design torna-se fator crucial no momento que se estudam alternativas de soluções durante o processo de projetação, entendendo que todo conhecimento adquirido na vida estudantil não é apenas para avançar etapas e sim acumulativo.

Devido o tempo limite da pesquisa, não foi possível finalizar todas as linhas de mobiliário criadas, todavia o projeto originou duas peças que proporcionaram um estudo mais aprofundado sobre materiais e o potencial do jupati, que ainda apresenta pouca bibliografia tanto de aspectos técnicos quanto sensoriais uma das dificuldades da pesquisa, e um olhar mais aguçado sobre a própria região amazônica- seus contrastes, formas, transformações, diversidades e simbolismos.

Os objetivos da pesquisa foram cumpridos e os resultados gerados satisfatórios. Constatou-se que o material é mais uma alternativa para a produção moveleira se aproximando do ideal sustentável que a pesquisa visou. Sendo mais um documento que enriquece a produção científica amazônica, espera-se que este trabalho contribua para futuras produções tendo como foco esta matéria-prima.

\section{Referências bibliográficas}

COSTA, Manuela; SIMÕES, Vanessa. Design de superfície e tradição artesanal: Produtos inspirados no artesanato em fibra de São Sebastião da Boa Vista. Trabalho de conclusão de curso (Bacharelado em Design). UEPA-PA, 2011.

JARDIM, Ninon Rose. Mulheres entre enfeites \& caminhos: cartografia de memórias em saberes e estéticas do cotidiano no Marajó das florestas (s.s. da boa vista - pa) / Ninon Rose Tavares Jardim. Belém, PA: - 2013.

. Design e Artesanato: Relatos de uma Experiência em São Sebastião da Boa Vista - Ilha do Marajó/Pará/Brasil.4o CIPED, 2007. Rio de Janeiro. Anais. Rio de Janeiro: AEND-BR, 2007.

NIEMEYER, Lucy. Elementos da semiótica aplicados ao design. Rio de Janeiro: 2AB, 2003.

JUPATÍ (RAPHIA TAEDIGERA MART.): A SUA UTILIZAÇÃO POR COMUNIDADES RIBEIRINHAS DO ESTADO DO PARÁ. Disponível em: <http://www.alice.cnptia.embrapa.br/handle/doc/575004> Acesso em 06 mar de 2017.

OLIVEIRA, Vanessa Cristina da. Desenvolvimento de um compósito estrutural do tipo sanduíche com núcleo da Raphia Taedigera: Avaliação mecânica. Dissertação de Mestrado - Programa de Pós Graduação em Engenharia Mecânica (PPGEM), Instituto de Tecnologia, Universidade Federal do Pará (Orientação: Profa. Dra. Carmen Gilda Barroso Tavares Dias): Belém, 2018.

Processo de extração e beneficiamento da fibra de buriti. Disponível em <http://artesanatocomdesign.blogspot.com.br/2011/11/processo-de-extracao-e-beneficiamento. html> Acesso em 06 mar de 2017.

SANTOS, Núbia Suely Silva. Análise experimental e teórica do comportamento mecânico sob carregamentos quase-estáticos de compósitos reforçados com fibras vegetais / Nubia Suely Silva Santos. Campinas, SP: [s.n.], 2010.

SODRÉ, José Barbosa. Morfologia das palmeiras como meio de identificação e uso paisagístico / José Barbosa Sodré. Lavras, MG: [s.n], 2005. 